\title{
Relationship between post-operative cognitive dysfunction and regional cerebral oxygen saturation and $\beta$-amyloid protein*
}

\author{
Xi-ming $\mathrm{LI}^{\dagger \$ 1,2}$, Ming-tao SHAO ${ }^{\S 3}$, Jian-juan $\mathrm{WANG}^{4}$, Yue-lan $\mathrm{WANG}^{\dagger \dagger 1}$ \\ ('Department of Anesthesiology, Affiliated Qianfoshan Hospital of Shandong University, Jinan 250014, China) \\ ( ${ }^{2}$ Department of Anesthesiology, Linyi City People's Hospital, Linyi 276000, China) \\ ( ${ }^{3}$ Department of Emergency Surgery, Linyi City People's Hospital, Linyi 276000, China) \\ ( ${ }^{4}$ Department of Anesthesiology, Shandong Lunan Ophthalmologic Hospital, Linyi 276000, China) \\ †E-mail: 13515397176@163.com; wyldgf@163.com \\ Received May 6, 2014; Revision accepted Aug. 7, 2014; Crosschecked Sept. 21, 2014
}

\begin{abstract}
Objective: To investigate the relationship between post-operative cognitive dysfunction (POCD) and regional cerebral oxygen saturation $\left(\mathrm{rSO}_{2}\right)$ and $\beta$-amyloid protein $(\mathrm{A} \beta)$ in patients undergoing laparoscopic pancreaticoduodenectomy. Methods: Fifty patients undergoing elective laparoscopic pancreaticoduodenectomy received five groups of neuropsychological tests $1 \mathrm{~d}$ pre-operatively and $7 \mathrm{~d}$ post-operatively, with continuous monitoring of $\mathrm{rSO}_{2}$ intra-operatively. Before anesthesia induction $\left(t_{0}\right)$, at the beginning of laparoscopy $\left(t_{1}\right)$, and at the time of pneumoperitoneum $120 \mathrm{~min}\left(t_{2}\right)$, pneumoperitoneum $240 \mathrm{~min}\left(t_{3}\right)$, pneumoperitoneum $480 \mathrm{~min}\left(t_{4}\right)$, the end of pneumoperitoneum $\left(t_{5}\right)$, and $24 \mathrm{~h}$ after surgery, jugular venous blood was drawn respectively for the measurement of $A \beta$ by enzyme-linked immunosorbent assay (ELISA). Results: Twenty-one cases of the fifty patients suffered from POCD after operation. We found that the maximum percentage drop in $\mathrm{rSO}_{2}\left(\mathrm{rSO}_{2}\right.$ \% max $)$ was significantly higher in the POCD group than in the non-POCD group. The $\mathrm{rSO}_{2}$, \% max value of over $10.2 \%$ might be a potential predictor of neurocognitive injury for those patients. In the POCD group, the plasma $A \beta$ levels after $24 \mathrm{~h}$ were significantly higher than those of pre-operative values $(P<0.01)$. After $24 \mathrm{~h}$, levels of plasma $A \beta$ in the POCD group were significantly higher than those in the non-POCD group $(P<0.01)$. Conclusions: The development of $P O C D$ in patients undergoing laparoscopic pancreaticoduodenectomy is associated with alterations of $\mathrm{rSO}_{2}$ and $\mathrm{A} \beta$. Monitoring of $\mathrm{rSO}_{2}$ might be useful in the prediction of $P O C D$, and $A \beta$ might be used as a sensitive biochemical marker to predict the occurrence of POCD.
\end{abstract}

Key words: Laparoscopic pancreaticoduodenectomy, Regional cerebral oxygen saturation, $\beta$-Amyloid protein, Post-operative cognitive dysfunction doi: $10.1631 /$ jzus.B1400130

Document code: A

CLC number: R74; R446.11 $1^{+}$

\section{Introduction}

The incidence of early post-operative cognitive dysfunction (POCD) can reach as high as $40 \%-50 \%$, which adversely affects quality of life and rehabilita-

\footnotetext{
${ }^{\ddagger}$ Corresponding author

${ }^{\S}$ The two authors contributed equally to this work

* Project supported by the Shandong Science and Technology Development Project (No. 2011YD18070), China

(C) Zhejiang University and Springer-Verlag Berlin Heidelberg 2014
}

tion of patients (Rohan et al., 2005). The underlying pathophysiological mechanism of POCD remains unclear.

Alzheimer's disease (AD) is a chronic progressive neurologic degeneration. Recent studies have shown that prolonged POCD increases the incidence of dementia (Vanderweyde et al., 2010; Bittner et al., 2011). Fodale et al., (2010) thought that the pathological mechanism of POCD is similar to that of AD. Also, the type of operation and anesthesia, differences in genes, central cholinergic system, $\beta$-amyloid 
protein $(A \beta)$, cholinergic system, older age, and anesthetics may also have impact on the development of POCD.

The possible risk factors contributing to the development of POCD include age, pre-operative cognitive function, operation time, hypoperfusion, embolism, post-operative pain, respiratory complications, and infections (Krenk et al., 2010). The proposition of intervention includes cerebral oxygen saturation monitoring and the control of the depth of anesthesia. In non-cardiac surgery, monitoring of regional cerebral oxygen saturation $\left(\mathrm{rSO}_{2}\right)$ has been proven to be important for improving the results of intervention factors (Casati et al., 2005; Farag et al., 2006; Slater et al., 2009).

Transcranial near-infrared spectroscopy (NIRS) provides a non-invasive method to detect $\mathrm{rSO}_{2}$. Recent studies have shown that the development of POCD had a significant relationship with the levels of $\mathrm{rSO}_{2}$ in patients undergoing coronary artery bypass graft (CABG) (Olsen et al., 1996; Murkin et al., 2007). The studies using NIRS have shown that there was a significant relationship between low $\mathrm{rSO}_{2}$ and neurologic complications, cognitive function, and prolonged hospitalization for the patients undergoing abdominal operation or CABG surgery under anesthesia (Monk et al., 2002; Goldman et al., 2004; Yao et al., 2004; Casati et al., 2005).

Laparoscopic pancreaticoduodenectomy has been widely used with reduced hospitalization time, fast recovery, and improved quality of life for patients. However, it also has some shortcomings; for example, compared with a conventional operation, its average operation time is up to $10 \mathrm{~h}$, average blood loss $139 \mathrm{ml}$, post-operation hospitalization time up to $6.6 \mathrm{~d}$ (Jacobs and Kamyab, 2013; Mesleh et al., 2013), and the incidence of cognitive dysfunction is higher than that of other abdominal surgery. It might have a strong relationship with operation time and anesthesia management.

In this study, we detected $\mathrm{rSO}_{2}$ and compared it with changes of plasma $A \beta$ levels to explore the relationship between post-operative cognitive function and $\mathrm{rSO}_{2}$ and plasma $\mathrm{A} \beta$ for the patients undergoing laparoscopic pancreaticoduodenectomy. We hypothesize that the changes of $\mathrm{A} \beta$ levels and $\mathrm{rSO}_{2}$ would be predictive factors for POCD in patients following this operation with general anesthesia.

\section{Materials and methods}

\subsection{Materials}

This study was approved by the Ethics Committee of Linyi City People's Hospital, China and obtained informed consent of all patients. Fifty patients, American Standards Association (ASA) classes II-III, were recruited from our hospital; they received laparoscopic pancreaticoduodenectomy from December 2010 to May 2013. There were 29 males and 21 females. The age range was 40 to 80 years old. Pre-operative imaging showed that there were 30 cases of pancreatic cancer affecting the body of the pancreas and 20 cases affecting the pancreatic tail. We abided by the following exclusion criteria: (1) pre-operative minimental state examination (MMSE) score less than 24; (2) a current or past history of psychiatric disorder or central nervous system disease; (3) a history of cardiovascular surgery or craniotomy; (4) drug or alcohol dependence; (5) hepatic failure; (6) renal failure; (7) inability to read or speak; and, (8) serious hearing or vision impairment (Lin et al., 2013).

\subsection{Anesthetic management}

All patients received a standardized anesthetic management. In the operating room, 5-ECG leads were attached, with leads II and $\mathrm{V}_{5}$ continuously monitored. A 20-G radial artery catheter was inserted to measure arterial blood pressure and arterial blood gas. A 7-Fr vein catheter introducer was inserted into the right internal jugular for mixed venous oxygen saturation $\left(\mathrm{SvO}_{2}\right)$ monitoring (Hong et al., 2008) and for blood sample collection to be used for $A \beta$ assay. Three electrodes connected with Narcotrend ${ }^{\circledR}$ monitor (Narcotrend $^{\circledR}$-Compact, MT Monitor Technik $\mathrm{GmbH}$ und Co. KG, Germany) and an $\mathrm{rSO}_{2}$ sensor connected with NIRS (INVOS 5100B, Somanetics, Troy, MI, USA) were placed on the skin of the forehead to separately record values of Narcotrend and $\mathrm{rSO}_{2}$ at 30-s intervals during surgery (Lin et al., 2013). After 5 min for equilibrium, Narcotrend and $\mathrm{rSO}_{2}$ readings were regarded as the baseline values.

Anesthesia was induced with midazolam 0.04$0.05 \mathrm{mg} / \mathrm{kg}$, propofol $1.0-1.5 \mathrm{mg} / \mathrm{kg}$, sufentanil 1.0 $1.5 \mu \mathrm{g} / \mathrm{kg}$, cis-atracurium $0.10-0.15 \mathrm{mg} / \mathrm{kg}$. After intubation, all patients were administered with propofol 2-5 $\mu \mathrm{g} /(\mathrm{kg} \cdot \mathrm{h})$, remifentanil $0.5-1.0 \mu \mathrm{g} /(\mathrm{kg} \cdot \mathrm{min})$, cis-atracurium $2-4 \mu \mathrm{g} /(\mathrm{kg} \cdot \mathrm{min})$, and inhalation of 
sevoflurane $(1 \%-3 \%)$. The intra-operative blood pressure and heart rate were maintained to allow fluctuation less than $30 \%$ of the baseline values. The Narcotrend index was kept between $\mathrm{D}_{1}$ and $\mathrm{E}_{1}$. All anesthesia-related data including dose of anesthetic agents, fluid input quantity, blood loss, the duration of operation and anesthesia, and recovery time were recorded routinely (Lin et al., 2013).

\subsection{Physiologic variables}

Physiologic variables including $\mathrm{SvO}_{2}$, arterial partial pressure of carbon dioxide $\left(\mathrm{PaCO}_{2}\right)$, arterial partial pressure of oxygen $\left(\mathrm{PaO}_{2}\right)$, glucose, and hematocrit were measured. The observation time points include: before induction of anesthesia $\left(t_{0}\right)$, before the start of pneumoperitoneum $\left(t_{1}\right)$, pneumoperitoneum $120 \min \left(t_{2}\right)$, pneumoperitoneum $240 \min \left(t_{3}\right)$, pneumoperitoneum $480 \mathrm{~min}\left(t_{4}\right)$, pneumoperitoneum end $\left(t_{5}\right)$, and $24 \mathrm{~h}$ after surgery. A Radiometer ABL800 automatic blood gas analyzer was used for blood gas analysis.

\subsection{Monitoring $\mathrm{rSO}_{2}$}

The $\mathrm{rSO}_{2}$ was detected by NIRS (Brawanski et al., 2002) using a near-infrared light spectrum analyzer INVOS5100 (Somaneti, USA). The $\mathrm{rSO}_{2}$ probe was placed on the right side of the forehead. The instrument can monitor continuously, record, and save the oxygen data automatically. The cerebral oxygen data were recorded twice per minute. These data were transferred to a computer for statistical processing after operation (Hong et al., 2008). Surgeons and anesthesiologists were blinded to the patients' group assignment and the measurement of $\mathrm{rSO}_{2}$ so as to exclude subjective bias.

\subsection{Analysis of plasma $A \beta$}

Plasma levels of the $A \beta$ were analyzed as a biomarker of brain injury. Blood samples were taken from participants at baseline and $1 \mathrm{~d}$ post-operatively. Five-ml jugular vein blood was collected into a procoagulant polyvinyl chloride (PVC) tube and placed in the refrigerator for $2 \mathrm{~h}$, and then centrifuged at $3000 \mathrm{r} / \mathrm{min}$ at $4{ }^{\circ} \mathrm{C}$ for $10 \mathrm{~min}$ to separate the serum. The supernatant was placed in a PVC tube and placed in cryogenic refrigerator at below $-20{ }^{\circ} \mathrm{C}$. The experimental specimens were set at room temperature before reconstitution and use. The Beta Amyloid 42 ELISA Kit was used (Covance Princeton, New Jersey, USA) and the assay was performed according to the instructions provided by the supplier to establish a standard curve; measured specimen OD values were calculated to obtain the protein content.

\subsection{Neurologic and neuropsychological assessments}

All eligible patients underwent a battery of clinical quantitative neurologic and neuropsychological tests on the day before operation and $7 \mathrm{~d}$ after operation. The control group did the same tests on the same days. The battery primarily focused on memory, learning, attention, executive functions, and cognitive flexibility, and encompassed the following tests: MMSE, digit symbol substitutions test (DSST), trail making test (part A), verbal fluency test (VFT), and word recognition memory tests. The same physician carried out the evaluation of cognitive function among patients and controls according to the methods of Lin et al. (2013). Learning effects were defined as mean variation of each test from baseline among control subjects. The tests were performed according to the International Study of Postoperative Cognitive Dysfunction (ISPOCD1 and ISPOCD2) (Moller et al., 1998; Johnson et al., 2002; Canet et al., 2003).

A $Z$ score for each individual test was calculated by comparing with baseline scores and with test results one week after surgery, by subtracting the average learning effect from these changes, and being divided by the standard deviation (SD) of the control group. POCD was defined as $Z$ scores equal to or greater than 1.96 on at least two tests (Moller et al., 1998; Johnson et al., 2002; Canet et al., 2003; Lin et al., 2013).

\subsection{Statistical analysis}

Statistical analysis was performed using SPSS 19.0 (IBM, Armonk, NY, USA). Continuous variables were expressed as mean $\pm \mathrm{SD}$ and processed with Student's $t$-test. Categorical variables were expressed as numbers (percentages) and processed with chisquare test or Fisher exact tests. Multivariate analysis of predictors for POCD was assessed with logistic regression. A $P$ value less than 0.05 was considered statistically significant. 


\section{Results}

\subsection{Incidence of POCD}

The clinical and demographic characteristics of the 50 patients and the comparison between POCD and non-POCD are presented in Table 1. Only 46 patients of the 50 performed the early cognitive post-test ( 2 patients did not participate the neurologic or neuropsychological tests, 2 patients were transferred to open pancreaticoduodenectomy). Of these 46 patients, 21 (45.7\%) showed early POCD because of the $Z$ score $\geq 1.96$. Advanced age and lower education level were significant pre-operative predictors for POCD (Hong et al., 2008). Basal body temperature was significantly higher in the POCD patients than in normal patients.

Table 1 Demographic and intra-operative data of the POCD and non-POCD groups

\begin{tabular}{|c|c|c|c|}
\hline Variable & $\begin{array}{c}\text { Non-POCD } \\
(n=25)\end{array}$ & $\begin{array}{l}\text { POCD } \\
(n=21)\end{array}$ & $P$ \\
\hline Age (year) & $65 \pm 5$ & $73 \pm 3$ & 0.010 \\
\hline Male/female & $8 / 17$ & $6 / 15$ & 0.529 \\
\hline Height $(\mathrm{cm})$ & $164 \pm 4$ & $161 \pm 5$ & 0.135 \\
\hline Weight (kg) & $62 \pm 6$ & $61 \pm 5$ & 0.611 \\
\hline Body mass index & $23.1 \pm 2.5$ & $23.4 \pm 1.3$ & 0.674 \\
\hline Education level (year) & $11 \pm 2.55$ & $8 \pm 2.65$ & 0.030 \\
\hline \multicolumn{4}{|l|}{ ASA physical status } \\
\hline II $(\%)$ & 48 & 47.6 & 0.607 \\
\hline III $(\%)$ & 52 & 52.4 & \\
\hline \multicolumn{4}{|c|}{ Pre-operative complication } \\
\hline Hypertension (\%) & 44 & 28.6 & 0.363 \\
\hline Diabetes $(\%)$ & 24 & 19.0 & 0.735 \\
\hline Smoking history $(\%)$ & 32 & 23.8 & 0.744 \\
\hline Surgical history (\%) & 48 & 47.6 & 0.493 \\
\hline $\begin{array}{l}\text { Duration of anesthesia } \\
\text { (min) }\end{array}$ & $562 \pm 30$ & $553 \pm 21$ & 0.230 \\
\hline $\begin{array}{l}\text { Duration of surgery } \\
\text { (min) }\end{array}$ & $530 \pm 30$ & $524 \pm 22$ & 0.493 \\
\hline Fluid replacement (ml) & $4480 \pm 157$ & $4524 \pm 162$ & 0.189 \\
\hline Blood loss (ml) & $141 \pm 18$ & $149 \pm 21$ & 0.198 \\
\hline Recovery time (min) & $32 \pm 5.2$ & $35 \pm 5.1$ & 0.079 \\
\hline Propofol (mg) & $2117.2 \pm 7.9$ & $2112.4 \pm 8.3$ & 0.051 \\
\hline Remifentanil (mg) & $6.51 \pm 0.13$ & $6.60 \pm 0.19$ & 0.062 \\
\hline cis-Atracurium (mg) & $27.5 \pm 2.66$ & $28.9 \pm 2.59$ & 0.082 \\
\hline$T_{\mathrm{a}}\left({ }^{\circ} \mathrm{C}\right)$ & $36.5 \pm 0.27$ & $36.9 \pm 0.3$ & $<0.001$ \\
\hline
\end{tabular}

Data are presented as mean \pm SD or the percentage of all patients. ASA: American Society of Anesthesiologists; $T_{\mathrm{a}}$ : axillary temperature

\subsection{Neurologic and neuropsychological tests}

Peri-operative congnitive function test scores are shown in Table 2. In the POCD group, post-operative scores of MMSE, DSST, and VFT were significantly lower than those at baseline $(P<0.05)$. Patients with POCD showed significant deterioration in learning and memory abilities and performance functional disorder, and were more anxious and depressed than non-POCD patients.

Table 2 Neuropsychological test results of the POCD and non-POCD groups

\begin{tabular}{|c|c|c|c|}
\hline \multirow[b]{2}{*}{ Test } & \multicolumn{2}{|c|}{ Score or time (s) } & \multirow[b]{2}{*}{$P$} \\
\hline & $\begin{array}{c}\text { Non-POCD } \\
(n=25)\end{array}$ & $\begin{array}{l}\text { POCD } \\
(n=21)\end{array}$ & \\
\hline \multicolumn{4}{|l|}{ MMSE } \\
\hline Pre-operative & $29.00 \pm 0.67$ & $29.30 \pm 0.34$ & 0.054 \\
\hline Pod\#7 & $28.83 \pm 0.68$ & $27.10 \pm 0.41^{*, * *}$ & $<0.001$ \\
\hline \multicolumn{4}{|l|}{ DSST } \\
\hline Pre-operative & $32.32 \pm 4.75$ & $31.00 \pm 4.23$ & 0.329 \\
\hline Pod\#7 & $29.96 \pm 4.86$ & $26.14 \pm 3.13^{*, * *}$ & 0.003 \\
\hline \multicolumn{4}{|c|}{ Trail making test A (s) } \\
\hline Pre-operative & $17.60 \pm 5.68$ & $19.40 \pm 5.62$ & 0.289 \\
\hline Pod\#7 & $17.84 \pm 6.06$ & $20.50 \pm 5.86$ & 0.140 \\
\hline \multicolumn{4}{|l|}{ VFT } \\
\hline Pre-operative & $16.70 \pm 1.77$ & $16.01 \pm 1.58$ & 0.180 \\
\hline Pod\#7 & $16.35 \pm 1.85$ & $14.51 \pm 1.71^{*, * *}$ & $<0.001$ \\
\hline \multicolumn{4}{|c|}{ Word recognition memory test } \\
\hline Pre-operative & $1.20 \pm 0.44$ & $1.30 \pm 0.48$ & 0.689 \\
\hline Pod\#7 & $1.40 \pm 0.43$ & $1.90 \pm 0.42$ & 0.965 \\
\hline
\end{tabular}

The test results (scores, except time (s) for trail making test A) are presented as mean \pm SD. Pod $\#$ 7: post-operative Day 7; MMSE: minimental state examination; DSST: digit symbol substitutions test; VFT: verbal fluency test. ${ }^{*} P<0.05$, vs. non-POCD group; ${ }^{* *} P<0.05$, vs. baseline in either group

\subsection{Physiologic variables}

$\mathrm{PaCO}_{2}$ was significantly higher at $t_{3}$ and $t_{4}$ in the POCD patients than in normal patients. $\mathrm{PaO}_{2}$ was significantly higher at $t_{1}$ to $t_{4}$ than at $t_{0}$ in all patients. Remaining variables including $\mathrm{SvO}_{2}$, glucose, and hematocrit did not significantly differ between groups (Table 3).

\subsection{Comparison of $\mathrm{rSO}_{2}$}

There were no statistical differences of $\mathrm{rSO}_{2}$, mean $\mathrm{rSO}_{2}\left(\overline{\mathrm{rSO}_{2}}\right)$, or minimum $\mathrm{rSO}_{2}\left(\mathrm{rSO}_{2}, \min \right)$ between the two groups at baseline. Compared with the non-POCD group, maximum percentage drop in $\mathrm{rSO}_{2}\left(\mathrm{rSO}_{2, \% \max }\right)$ was observably greater in the POCD group $(P=0.001)$ (Table 4$)$. 
Table 3 Comparison of physiologic variables between the POCD and non-POCD groups

\begin{tabular}{|c|c|c|c|c|c|c|c|c|c|c|}
\hline \multirow{2}{*}{ Time } & \multicolumn{2}{|c|}{$\mathrm{SvO}_{2}(\%)$} & \multicolumn{2}{|c|}{$\mathrm{PaCO}_{2}(\mathrm{mmHg})$} & \multicolumn{2}{|c|}{$\mathrm{PaO}_{2}(\mathrm{mmHg})$} & \multicolumn{2}{|c|}{ Glucose $(\mathrm{mg} / \mathrm{dl})$} & \multicolumn{2}{|c|}{ Hematocrit (\%) } \\
\hline & Non-POCD & POCD & Non-POCD & POCD & Non-POCD & POCD & Non-POCD & POCD & Non-POCD & POCD \\
\hline$t_{0}$ & $81 \pm 13$ & $83 \pm 9$ & $33 \pm 6$ & $34 \pm 4$ & $277 \pm 56$ & $267 \pm 66$ & $123 \pm 26$ & $115 \pm 20$ & $30 \pm 7$ & $31 \pm 6$ \\
\hline$t_{1}$ & $78 \pm 10$ & $80 \pm 11$ & $37 \pm 7$ & $37 \pm 6$ & $361 \pm 54$ & $341 \pm 34$ & $152 \pm 68$ & $162 \pm 63$ & $29 \pm 5$ & $28 \pm 6$ \\
\hline$t_{2}$ & $75 \pm 9$ & $78 \pm 9$ & $38 \pm 8$ & $39 \pm 8$ & $362 \pm 31$ & $342 \pm 38$ & $206 \pm 62$ & $216 \pm 72$ & $27 \pm 6$ & $26 \pm 7$ \\
\hline$t_{3}$ & $73 \pm 6$ & $76 \pm 7$ & $43 \pm 7$ & $49 \pm 6^{*}$ & $358 \pm 52$ & $341 \pm 42$ & $208 \pm 57$ & $220 \pm 68$ & $26 \pm 5$ & $25 \pm 8$ \\
\hline$t_{4}$ & $72 \pm 7$ & $73 \pm 8$ & $45 \pm 6$ & $51 \pm 7^{*}$ & $340 \pm 33$ & $336 \pm 28$ & $212 \pm 49$ & $214 \pm 52$ & $25 \pm 8$ & $23 \pm 5$ \\
\hline$t_{5}$ & $78 \pm 9$ & $79 \pm 10$ & $36 \pm 8$ & $40 \pm 6$ & $279 \pm 76$ & $249 \pm 80$ & $133 \pm 36$ & $124 \pm 34$ & $24 \pm 8$ & $23 \pm 8$ \\
\hline
\end{tabular}

Data are presented as mean $\pm \mathrm{SD} ; \mathrm{SvO}_{2}$ : mixed venous oxygen saturation; $\mathrm{PaCO}_{2}$ : arterial partial pressure of carbon dioxide; $\mathrm{PaO}$ : arterial partial pressure of oxygen. ${ }^{*} P<0.05$, vs. non-POCD group

Table 4 Comparison of baseline $\mathrm{rSO}_{2}, \overline{\mathrm{rSO}_{2}}, \mathrm{rSO}_{2}$, min, and $\mathrm{rSO}_{2, \% \max }$ between the POCD and non-POCD groups

\begin{tabular}{ccccc}
\hline Group & $\begin{array}{c}\text { Baseline } \\
(\%)\end{array}$ & $\begin{array}{c}\overline{\mathrm{rSO}_{2}} \\
(\%)\end{array}$ & $\begin{array}{c}\mathrm{rSO}_{2, \min } \\
(\%)\end{array}$ & $\begin{array}{c}\mathrm{rSO}_{2, \% \max } \\
(\%)\end{array}$ \\
\hline Non-POCD & 69 & 71 & 62 & 8.64 \\
$(n=25)$ & $(67-71)$ & $(69-74)$ & $(59-64)$ & $(6.7-12.0)$ \\
POCD & 69 & 69 & 59 & 13 \\
$(n=21)$ & $(63-75)$ & $(61-76)$ & $(52-66)$ & $(8.3-18.5)^{*}$ \\
\hline$P$ & 0.855 & 0.427 & 0.445 & $<0.001$ \\
\hline
\end{tabular}

Data are presented as median (5th-95th percentile). $\mathrm{rSO}_{2}$ : regional cerebral oxygen saturation; $\overline{\mathrm{rSO}_{2}}$ : mean $\mathrm{rSO}_{2} ; \mathrm{rSO}_{2}$, min : minimum $\mathrm{rSO}_{2} ; \mathrm{rSO}_{2, \% \max }$ : maximum percentage drop in $\mathrm{rSO}_{2} .{ }^{*} P<0.05$, vs. non-POCD group

Fig. 1 is a line chart of patients' intra-operative $\mathrm{rSO}_{2}$ trends of the two groups. The $\mathrm{rSO}_{2}$ values of the two groups at different time points were statistically significantly different $(P<0.05)$. In contrast, the trends of intra-operative $\mathrm{rSO}_{2}$ values were similar in the two groups.

$\mathrm{rSO}_{2, \% \max }$ was observably greater in the POCD group $(P<0.01)$. Fig. 2 displays receiver operating characteristic (ROC) curve of $\mathrm{rSO}_{2, \% \max }$, and the area under the curve (AUC) of which was 0.926 (95\% confidence interval (CI) $[0.842,1.000])$. When $\mathrm{rSO}_{2, \% \max }>10.2 \%$ was taken as the cut-off value, the specificity and sensitivity of $\mathrm{rSO}_{2, \% \max }$ in predicting POCD were $88.0 \%$ and $85.7 \%$, respectively.

\subsection{A $\beta$ levels}

In the POCD group, the plasma $A \beta$ levels after $24 \mathrm{~h}$ were statistically significantly higher than preoperative values $((100.27 \pm 6.79) \mathrm{pg} / \mathrm{ml}$ vs. $(78.90 \pm$ $11.07) \mathrm{pg} / \mathrm{ml} ; P<0.01)$. After $24 \mathrm{~h}$, the levels of plasma $\mathrm{A} \beta$ in the POCD group were significantly higher than those in the non-POCD group $((100.27 \pm 6.79) \mathrm{pg} / \mathrm{ml}$ vs. $(78.23 \pm 11.16) \mathrm{pg} / \mathrm{ml} ; P<0.01$ ) (Table 5).

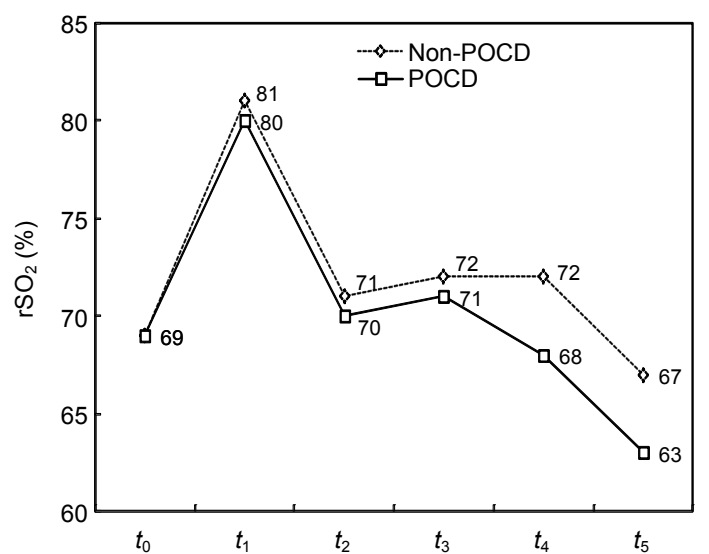

Fig. $1 \mathrm{rSO}_{2}$ trends in the POCD and non-POCD groups

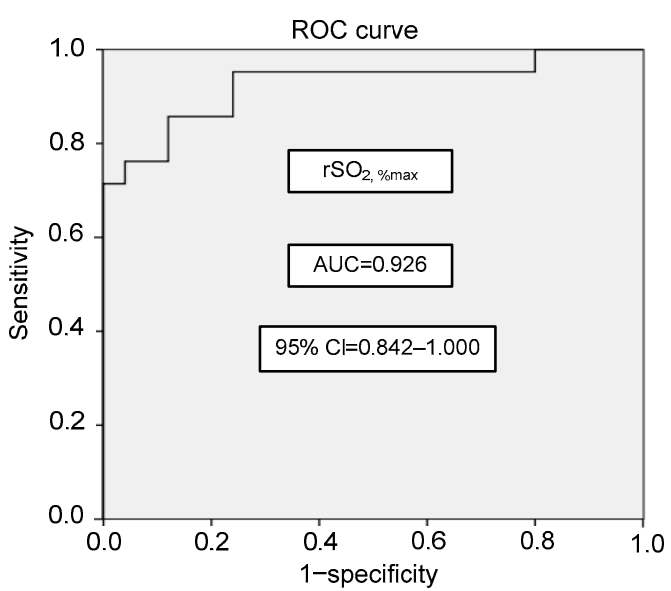

Fig. 2 Receiver operating characteristic (ROC) curves of $\mathrm{rSO}_{2, \% \max }$

AUC: area under the curve; CI: confidence interval

Results from risk factor analysis are presented in Table 6. In a multivariate logistic regression analysis, higher levels of basal body temperature, $\mathrm{rSO}_{2}$, \% max, $\mathrm{PaCO}_{2}$, and $\mathrm{A} \beta$ were significant intra-operative predictors for POCD. 
Table 5 -Amyloid protein (A $\beta$ ) levels of the POCD and non-POCD groups

\begin{tabular}{cccr}
\hline \multirow{2}{*}{ Time } & \multicolumn{2}{c}{$\mathrm{A} \beta$ level $(\mathrm{pg} / \mathrm{ml})$} & \multirow{2}{*}{$P$} \\
\cline { 2 - 3 } & Non-POCD $(n=25)$ & $\operatorname{POCD}(n=21)$ & \\
\hline$t_{0}$ & $78.11 \pm 11.25$ & $78.90 \pm 11.07$ & 0.990 \\
$t_{1}$ & $78.24 \pm 9.31$ & $83.98 \pm 9.83$ & 0.076 \\
$t_{2}$ & $79.11 \pm 11.60$ & $85.28 \pm 9.73^{* *}$ & 0.060 \\
$t_{3}$ & $80.72 \pm 11.55$ & $90.88 \pm 9.66^{*, * *}$ & 0.003 \\
$t_{4}$ & $89.65 \pm 10.73^{* *}$ & $101.70 \pm 9.25^{*, * *}$ & $<0.001$ \\
$t_{5}$ & $91.23 \pm 11.33^{* *}$ & $114.57 \pm 10.27^{* * * *}$ & $<0.001$ \\
$24 \mathrm{~h}$ & $78.23 \pm 11.16$ & $100.27 \pm 6.79^{*, * *}$ & $<0.001$ \\
\hline
\end{tabular}

Data are presented as mean \pm SD. ${ }^{*} P<0.05$, vs. non-POCD group; ${ }^{* * *} P<0.05$, vs. baseline in either group

Table 6 Analysis of risk factors to POCD

\begin{tabular}{lcc}
\hline \multicolumn{1}{c}{ Variable } & OR $(95 \% \mathrm{CI})$ & $P$ \\
\hline Age & $0.305(1.135-2.865)$ & 0.052 \\
Gender & $0.021(0.288-0.369)$ & 0.807 \\
Level of education & $0.087(0.021-1.979)$ & 0.236 \\
Basal body temperature & $0.391(1.539-2.461)$ & 0.002 \\
$\mathrm{PaCO}_{2}$ & $0.425(1.447-2.553)$ & 0.005 \\
$\mathrm{rSO}_{2, \% \max }$ & $0.794(0.056-0.103)$ & $<0.001$ \\
$\mathrm{~A} \beta$ & $0.577(0.020-0.033)$ & $<0.001$ \\
\hline
\end{tabular}

OR: odds ratio; CI: confidence interval

\section{Discussion}

POCD is a common post-anesthetic neurologic complication, manifested as mental confusion, anxiety, personality changes, and memory impairment. The pathogenesis of POCD is not clear, although it can be influenced by many factors. Most researchers think that POCD is related with age, operation, anesthesia, psychologic factors, sleeping disorder, and pain. There is no consistent outlook about POCD from the literature. The review reported by ISPOCD1 in 1998 was generally accepted. The incidence of POCD from 1218 elderly patients undergoing operation was $25.8 \%$ (Moller et al., 1998). In the study of Evered et al. (2011), the incidence of POCD at $7 \mathrm{~d}$ post-operation from 644 patients with CABG or total hip joint replacement (THJR) was $43 \%$ and $17 \%$, respectively. Rasmussen et al. (1999) observed that 17 elderly patients ( $\geq 60$ years) from 35 cases who received abdominal operation with general anesthesia developed POCD (48.6\%).
In our study, the incidence of POCD with laparoscopic pancreaticoduodenectomy was up to $45.7 \%$. The risk factors included advanced age and lower level education. These results are similar to other findings (Hong et al., 2008; de Tournay-Jetté et al., 2010). Interestingly, higher basal body temperature might be a significant predictor for POCD based on multivariate logistic regression analysis. Whether the patients with higher basal body temperature were in a proinflammatory state or a pronounced systemic inflammation pre-operatively was not assessed in this study. Regarding the relationship between metabolic imbalance caused by systemic inflammatory reaction and psychomotor slowing (Bokeriia et al., 2005), further evaluation of the effect of peri-operative inflammatory state and body temperature on POCD seems to be required (Hong et al., 2008). The development of POCD may be associated with operation, anesthesia type, evaluation methods of POCD, and diagnostic criteria. In addition, small sample size may also lead to bias of the incidence.

Laparoscopic pancreaticoduodenectomy is one of the mostly reported and "popular" laparoscopic pancreatic surgical procedures, which may offer many benefits to patients, such as shorter length of hospital stay, fewer complications, and improved quality of life, but the average operative time is up to $10 \mathrm{~h}$. The incidence of POCD after operation is also high (Jacobs and Kamyab, 2013; Mesleh et al., 2013). This may be associated with hypercarbia induced by the long duration of pneumoperitoneum and $\mathrm{CO}_{2}$ absorption through the peritoneum. Hypercarbia may cause reduction of $\mathrm{rSO}_{2}$. Another possible reason for causing reduction of $\mathrm{rSO}_{2}$ is cerebral vasodilation and increased intracranial pressure induced by increased $\mathrm{CO}_{2}$ (Germon et al., 1995; Konishi and Kikuchi, 1996).

$\mathrm{CO}_{2}$ is a powerful regulator of cerebrovasculature. Cerebral blood flow will increase or decrease by $2 \mathrm{ml} /(100 \mathrm{~g} \cdot \mathrm{min})$ correspondingly whenever $\mathrm{PaCO}_{2}$ increases or decreases $0.13 \mathrm{kPa}(1 \mathrm{mmHg})$. Although in normal circumstances, increasing cerebral blood flow will not decrease intracranial pressure and cerebral perfusion with the presence of intracranial compliance, we cannot evaluate whether increasing intracranial pressure and decreasing cerebral blood flow will result in $\mathrm{rSO}_{2}$ reduction on the basis of expanded cerebrovasculature after inhalational anesthesia. 
In a large prospective study (Monk et al., 2002), the incidence of POCD in elderly patients correlated with intra-operative frequently low $\mathrm{rSO}_{2}$. It is reported that $\mathrm{rSO}_{2}$ lower than $50 \%$ or a decrease in $\mathrm{rSO}_{2}$ of $20 \%$ compared to baseline will prognosticate the possible presence of cerebral ischemia. This conclusion had been proven by the auditory evoked potential test (Blas et al., 1999). Slater et al. (2009) also came to a similar conclusion. The patients with $\mathrm{rSO}_{2}$ score decreasing $\geq 3000 \% \cdot s$ in CABG intra-operation would be more likely to develop POCD $(P=0.024)$. The risk increases nearly three-fold with prolonged hospital stay.

In our study, the $\mathrm{rSO}_{2,} \%$ max in the POCD group was significantly higher than that in the non-POCD group $(P<0.001)$. In the non-POCD group, $t_{1}-t_{4} \mathrm{rSO}_{2}$ values were significantly higher than $t_{0} \mathrm{rSO}_{2}$ value $(P<0.05)$. There was no significant difference between $\mathrm{rSO}_{2}$ values at $t_{5}$ and $t_{0}$. In the POCD group, $\mathrm{rSO}_{2}$ at $t_{1}$ was significantly higher than that at $t_{0}$ $(P<0.05)$, while at $t_{5}$ it decreased significantly compared with $t_{0}(P<0.05)$. These data demonstrated that the $\mathrm{rSO}_{2}$ could correspond to the occurrence of POCD It was also highlighted that $\mathrm{rSO}_{2, \% \max }>10.2 \%$ was a potential predictor of neurocognitive injury.

$\mathrm{A} \beta$ is a polypeptide with a folded configuration and $\beta$ sheet structure formed by $39-43$ amino acids. The molecular weight is about $4 \mathrm{kD}$. $\mathrm{A} \beta$ is an initiating factor of senile plaque formation and the important component of senile plaque nucleus for $\mathrm{AD}$. There is a close relationship between increased $A \beta$ and cognitive dysfunction (Townsend et al., 2002). The increased brain $A \beta$ was related to increased $A \beta$ precursor protein ( $\beta$-APP) (Grilli et al., 1996). APP is an acute reactive protein that is modulated by central inflammatory cytokines in transcription (Grilli et al., 1996). The generation and accumulated increase of $\mathrm{A} \beta$ would further trigger neuronal apoptosis. $A \beta$ can induce NMDA receptors and block transmission of information in neurons, resulting in dysfunction for learning and memory. Sevoflurane can alter the formation of amyloid precursor protein and increase the level of $\mathrm{A} \beta$, which would result in neurotoxicity. $\mathrm{Lu}$ et al. (2010) also reported that $\mathrm{AD}$ transgenic rats are prone to neurologic injury on inhalation of sevoflurane.

Neurodegeneration and anesthesia may be contributing factors to the pathophysiology of POCD (Tang et al., 2010). Inflammation is the bridge be- tween POCD and AD; therefore, surgery and anesthesia may lead to brain inflammation, which may be one of the mechanisms of the increased incidence of POCD (Hu et al., 2010).

Recent studies show that $A \beta$ is one of the potential markers of neurologic damage and persistent inflammation (Gold et al., 2005). A $\beta$ may be associated with increased cognitive dysfunction. A potential relationship between $A \beta$ and POCD may exist and serve as one of the predictors of the increased incidence of POCD and other related biomarkers (Townsend et al., 2002).

Multivariate logistic regression analysis has shown that basal body temperature, $\mathrm{PaCO}_{2}, \mathrm{rSO}_{2}$, \% max and $\mathrm{A} \beta$ seem to play a more important role for the interpretation of POCD. Routine blood gas analysis, monitoring of $\mathrm{rSO}_{2}$, and detection of plasma $\mathrm{A} \beta$ might be useful tools for predicting the occurrence of POCD. Further studies are required to investigate the importance of plasma $A \beta$ as a potential biomarker for POCD. Findings from the current study may have a significant impact on the promotion and application of laparoscopic pancreaticoduodenectomy and the improvement of prognosis.

\section{Acknowledgements}

We sincerely thank Dr. Xiang-wei ZHANG (an anesthesiologist of the Massachusetts General Hospital, USA) for providing valuable help in this study.

\section{Compliance with ethics guidelines}

Xi-ming LI, Ming-tao SHAO, Jian-juan WANG, and Yue-lan WANG declare that they have no conflict of interest.

All procedures followed were in accordance with the ethical standards of the responsible committee on human experimentation (institutional and national) and with the Helsinki Declaration of 1975, as revised in 2008 (5). Informed consent was obtained from all patients for being included in the study. Additional informed consent was obtained from all patients for which identifying information is included in this article.

\section{References}

Bittner, E.A., Yue, Y., Xie, Z., 2011. Brief review: anesthetic neurotoxicity in the elderly, congnitive dysfunction and Alzheimer's disease. Can. J. Anesth., 58(2):216-223. [doi:10.1007/s12630-010-9418-x]

Blas, M., Sulek, C., Martin, T., et al., 1999. Use of near infrared spectroscopy to monitor cerebral oxygen at ion during coronary artery bypass surgery in a patient with bilateral internal carotid artery occlusion. J. Cardioth. 
Vasc. Anesth., 13(6):732-735. [doi:10.1016/S1053-0770 (99)90131-3]

Bokeriia, L.A., Golukhova, E.Z., Polunina, A.G., et al., 2005. Neural correlates of cognitive dysfunction after cardiac surgery. Brain Res. Rev., 50(2):266-274. [doi:10.1016/ j.brainresrev.2005.08.001]

Brawanski, A., Fahermeier, R., Rothoerl, R.D., et al., 2002. Comparison of near infrared spectroscopy and tissue $\mathrm{PO}_{2}$ time series in patients after severe head injury and an eurysmal subarachnoid hemorrhage. J. Cereb. Blood Flow Metab., 22(5):605-611. [doi:10.1097/00004647200205000-00012]

Canet, J., Raeder, J., Rasmussen, L.S., et al., 2003. Cognitive dysfunction after minor surgery in the elderly. Acta Anaesthesiol. Scand., 47(10):1204-1210. [doi:10.1046/j. 1399-6576.2003.00238.x]

Casati, A., Fanelli, G., Pietropaoli, P., et al., 2005. Continuous monitoring of cerebral oxygen saturation in elderly patients undergoing major abdominal surgery minimizes brain exposure to potential hypoxia. Anesth. Analg., 101(3):740-747. [doi:10.1213/01.ane.0000166974.96219.cd]

de Tournay-Jetté, E., Dupuis, G., Bherer, L., et al., 2010. The relationship between cerebral oxygen saturation changes and postoperative cognitive dysfunction in elderly patients after coronary artery bypass graft surgery. J. Cardiothorac. Vasc. Anesth., 24(1):95-104. [doi:10.1053/j. jvca.2010.03.019]

Evered, L., Scott, D.A., Silbert, B., et al., 2011. Postoperative cognitive dysfunction is independent of type of surgery and anesthetic. Anesth. Analg., 112(5):1179-1185. [doi:10. 1213/ANE.0b013e318215217e]

Farag, E., Chelune, G.J., Schubert, A., et al., 2006. Is depth of anaesthesia, as assessed by Bispectral Index, related to post-operative cognitive dysfunction and recovery? Anesth. Analg., 103(3):633-640. [doi:10.1213/01.ane.000 0228870.48028.b5]

Fodale, V., Santamaria, L.B., Schifilliti, D., et al., 2010. Anaesthetics and postoperative cognitive dysfunction: a pathological mechanism mimicking Alzheimer's disease. Anaesthesia, 65(4):388-395. [doi:10.1111/j.1365-2044. 2010.06244.x]

Germon, T.J., Young, A.E., Manara, A.R., et al., 1995. Extracerebral absorption of near infrared light influences the detection of increased cerebral oxygenation monitored by near infrared spectroscopy. J. Neurol. Neurosurg. Psychiatry, 58(4):477-479. [doi:10.1136/jnnp.58.4.477]

Gold, S.M., Dziobek, I., Rogers, K., et al., 2005. Hypertension and hypothalamo-pituitary-adrenal axis hyperactivity affect frontal lobe integrity. J. Clin. Endocrinol. Metab., 90(6):3262-3267. [doi:10.1210/jc.2004-2181]

Goldman, S., Sutter, F., Ferdinand, F., et al., 2004. Optimizing intraoperative cerebral oxygen delivery using noninvasive cerebral oximetry decreases the incidence of stroke for cardiac surgical patients. Heart Surg. Forum, 7(5): 376-381. [doi:10.1532/HSF98.20041062]

Grilli, M., Goffi, F., Memo, M., et al., 1996. Interleukin-1 $\beta$ and glutamate activate the NF- $\mathrm{kB} /$ Rel binding site from the regulatory region of the amyloid precursor protein gene in primary neuronal cultures. J. Biol. Chem., 271(25):15002-15007. [doi:10.1074/jbc.271.25.15002]

Hong, S.W., Shim, J.K., Choi, Y.S., et al., 2008. Prediction of cognitive dysfunction and patients' outcome following valvular heart surgery and the role of cerebral oximetry. Eur. J. Cardiothorac. Surg., 33(4):560-565. [doi:10. 1016/j.ejcts.2008.01.012]

Hu, Z., Ou, Y., Duan, K., et al., 2010. Inflammation: a bridge between postoperative cognitive dysfunction and Alzheimer's disease. Med. Hypotheses, 74(4):722-724. [doi:10.1016/j.mehy.2009.10.040]

Jacobs, M.J., Kamyab, A., 2013. Total laparoscopic pancreaticoduodenectomy. JSLS, 17(2):188-193. [doi:10.4293/ 108680813X13654754534792]

Johnson, T., Monk, T., Rasmussen, L.S., et al., 2002. Postoperative cognitive dysfunction in middle-aged patients. Anesthesiology, 96(6):1351-1357. [doi:10.1097/00000 542-200206000-00014]

Konishi, A., Kikuchi, K., 1996. Association of postoperative brain dysfunction and atherosclerosis, intraoperative $\mathrm{rSO}_{2}$ and $\mathrm{CO}_{2}$ reaction in open heart surgery. Masui, 45(3): 287-292 (in Japanese).

Krenk, L., Rasmussen, L.S., Kehlet, H., 2010. New insights into the pathophysiology of postoperative cognitive dysfunction. Acta Anaesthesiol. Scand., 54(8):951-956. [doi:10.1111/j.1399-6576.2010.02268.x]

Lin, R., Zhang, F.J., Xue, Q.S., et al., 2013. Accuracy of regional cerebral oxygen saturation in predicting postoperative cognitive dysfunction after total hip arthroplasty. $J$. Arthroplasty, 28(3):494-497. [doi:10.1016/j.arth.2012.06. 041]

Lu, Y., Wu, X., Dong, Y., et al., 2010. Anesthetic sevoflurane causes neurotoxicity differently in neonatal naive and Alzheimer disease transgenic mice. Anesthesiology, 112(6): 1404-1416. [doi:10.1097/ALN.0b013e3181d94de1]

Mesleh, M.G., Stauffer, J.A., Bowers, S.P., et al., 2013. Cost analysis of open and laparoscopic pancreaticoduodenectomy: a single institution comparison. Surg. Endosc., 27(12):4518-4523. [doi:10.1007/s00464-013-3101-6]

Moller, J.T., Cluitmans, P., Rasmussen, L.S., et al., 1998. Long-term postoperative cognitive dysfunction in the elderly ISPOCD1 study. Lancet, 351(9106):857-861. [doi:10.1016/S0140-6736(97)07382-0]

Monk, T.G., Weldon, B.C., Weldon, J.E., 2002. Cerebral oxygen desaturations are associated with postoperative cognitive dysfunction in elderly patients. Anesthesiology, 96:A40.

Murkin, J.M., Adams, S.J., Novick, R.J., et al., 2007. Monitoring brain oxygen saturation during coronary bypass surgery: a randomized, prospective study. Anesth. Analg., 104(1):51-58. [doi:10.1213/01.ane.0000246814.29362.f4]

Olsen, K.S., Svendsen, L.B., Larsen, F.S., 1996. Validation of transcranial near-infrared spectroscopy for evaluation of cerebral blood flow autoregulation. J. Neurosurg. Anesthesiol., 8(4):280-285. [doi:10.1097/00008506-199610000-00004] 
Rasmussen, L.S., Steentoft, A., Rasmussen, H., et al., 1999. Benzodiazepines and postoperative cognitive dysfunction in the elderly. Br. J. Anaesth., 83(4):585-589. [doi:10. 1093/bja/83.4.585]

Rohan, D., Buggy, D.J., Crowley, S., et al., 2005. Increased incidence of postoperative cognitive dysfunction $24 \mathrm{hr}$ after minor surgery in the elderly. Can. J. Anaesth., 52(2):137-142. [doi:10.1007/BF03027718]

Slater, J.P., Guarino, T., Stack, J., et al., 2009. Cerebral oxygen desaturation predicts cognitive decline and longer hospital stay after cardiac surgery. Ann. Thorac. Surg., 87(1): 36-44. [doi:10.1016/j.athoracsur.2008.08.070]

Tang, J., Eckenhoff, M.F., Eckenhoff, R.G., 2010. Anesthesia and the old brain. Anesth. Analg., 110(2):421-426. [doi:10.1213/ANE.0b013e3181b80939]
Townsend, K.P., Obregon, D., Quadros, A., et al., 2002. Proinflammatory and vasoactive effects of A $\beta$ in the cerebrovasculature. Ann. N. Y. Acad. Sci., 977(1):65-76. [doi:10.1111/j.1749-6632.2002.tb04799.x]

Vanderweyde, T., Bednar, M.M., Forman, S.A., et al., 2010. Iatrogenic risk factors for Alzheimer's disease: surgery and anesthesia. J. Alzheimer's Dis., 22(Suppl. 3):91-104. [doi:10.3233/JAD-2010-100843]

Yao, F.S., Tseng, C.C., Ho, C.Y., et al., 2004. Cerebral oxygen desaturation is associated with early postoperative neuropsychological dysfunction in patients undergoing cardiac surgery. J. Cardiothorac. Vasc. Anesth., 18(5): 552-558. [doi:10.1053/j.jvca.2004.07.007]

\section{中文概要:}

\section{本文题目: 术后认知功能障碍与脑氧饱和度及血浆 $\boldsymbol{\beta}$-淀粉样蛋白的关系}

Relationship between post-operative cognitive dysfunction and regional cerebral oxygen saturation and $\beta$-amyloid protein

研究目的：探讨腹腔镜胰体尾切除术患者术后认知功能障碍（POCD）的发生与脑氧饱和度 $\left(\mathrm{rSO}_{2}\right)$ 及血 浆 $\beta$-淀粉样蛋白 $(A \beta)$ 水平的相关性。

创新要点: $\mathrm{POCD}$ 的发生机制与 $\mathrm{rSO}_{2}$ 及 $\mathrm{A} \beta$ 有一定的相关性; $\mathrm{rSO}_{2}$ 较基础值下降的最大百分数 $\left(\mathrm{rSO}_{2, \% \max }\right)>10.2 \%$ 有可能发生 POCD，因此， $\mathrm{rSO}_{2}$ 监测可能是预测 POCD 发生的有效工具; $\mathrm{A} \beta$ 可能是发生 POCD 敏感的生化预警指标。

研究方法：择期行腹腔镜胰十二指肠切除术患者 50 例, 于术前 1 天和术后 7 天分别行简明精神状态量表 (MMSE) 、数字广度、数字符号、循迹连线、词汇流畅性（VFT）和单词辨认神经心理测验。 分别于麻醉诱导前 $\left(t_{0}\right)$ 、气腹开始前 $\left(t_{1}\right)$ 、气腹 $120 \mathrm{~min}\left(t_{2}\right)$ 、气腹 $240 \mathrm{~min}\left(t_{3}\right)$ 、气腹 $480 \mathrm{~min}\left(t_{4}\right)$ 、气腹结束 $\left(t_{5}\right)$ 及术毕 $24 \mathrm{~h}$, 抽取颈内静脉血 $3 \mathrm{ml}$, 采用酶联免疫法 (ELISA) 方法测定 $\mathrm{A} \beta$ 含量。术中利用近红外光谱技术（NIRS）连续监测 $\mathrm{rSO}_{2}$ ，并计算术中 $\mathrm{rSO}_{2}$ 平均 值 $\left(\overline{\mathrm{rSO}_{2}}\right)$ 、术中 $\mathrm{rSO}_{2}$ 最小值 $\left(\mathrm{rSO}_{2, \min }\right)$ 和 $\mathrm{rSO}_{2, \% \max }$ 。

重要结论: $\mathrm{POCD}$ 的发生与 $\mathrm{rSO}_{2}$ 及 $\mathrm{A} \beta$ 有关; 危险因素可能有老年、低教育水平、较高基础体温、 $\mathrm{rSO}_{2}$ 下降、 $\mathrm{CO}_{2}$ 蓄积、血浆 $\mathrm{A} \beta$ 升高等; $\mathrm{rSO}_{2}$ 监测有可能是 $\mathrm{POCD}$ 的有效预测工具之一; $\mathrm{A} \beta$ 有可能是发生 POCD敏感的生化预警标志物之一。

关键词组: 术后认知功能障碍; 局部脑氧饱和度; $\beta$-淀粉样蛋白 